Table 1: Basic demographic information of the survey responders. SD = standard deviation.

\begin{tabular}{|c|c|}
\hline Age in years (mean \pm SD) & $43.0 \pm 8.6$ \\
\hline \multicolumn{2}{|l|}{ Gender } \\
\hline Male & $71(88.8 \%)$ \\
\hline Female & $9(11.2 \%)$ \\
\hline \multicolumn{2}{|l|}{ Type of hospital/employment } \\
\hline University/teaching hospital & $73(91.3 \%)$ \\
\hline Other public hospital & $5(6.3 \%)$ \\
\hline Private hospital & $2(2.4 \%)$ \\
\hline \multicolumn{2}{|l|}{ Country of training } \\
\hline Austria & $2(2.5 \%)$ \\
\hline Belgium & $2(2.5 \%)$ \\
\hline Estonia & $1(1.3 \%)$ \\
\hline Finland & $4(5.0 \%)$ \\
\hline France & $16(20.0 \%)$ \\
\hline Germany & $12(15.0 \%)$ \\
\hline Greece & $1(1.3 \%)$ \\
\hline Israel & $1(1.3 \%)$ \\
\hline Italy & $1(1.3 \%)$ \\
\hline Kazakhstan & $1(1.3 \%)$ \\
\hline Lithuania & $1(1.3 \%)$ \\
\hline Norway & $7(8.8 \%)$ \\
\hline Serbia & $7(8.8 \%)$ \\
\hline Sweden & $4(5.0 \%)$ \\
\hline Switzerland & $9(11.3 \%)$ \\
\hline United Kingdom & $11(13.8 \%)$ \\
\hline Length of residency (mean \pm SD) & $6.1 \pm 1.4$ \\
\hline \multicolumn{2}{|l|}{ Year of residency graduation } \\
\hline $1976-1980$ & $1(1.3 \%)$ \\
\hline $1986-1990$ & $2(2.5 \%)$ \\
\hline $1991-1995$ & $5(6.3 \%)$ \\
\hline $1996-2000$ & $6(7.5 \%)$ \\
\hline $2001-2005$ & $8(10.0 \%)$ \\
\hline $2006-2010$ & $12(15.0 \%)$ \\
\hline $2011-2015$ & $20(25.0 \%)$ \\
\hline $2016-2018$ & 26 (32.5\%) \\
\hline
\end{tabular}




\begin{tabular}{|c|l|}
\hline No & $62(77.5 \%)$ \\
Yes & $18(22.5 \%)$ \\
\hline Total & $\mathbf{n = 8 0 ( 1 0 0 \% )}$ \\
\hline
\end{tabular}


Table 2: Overview on the caseloads of certain types of procedures, performed on average during neurosurgery residency in Europe. $\mathrm{Cl}=$ confidence interval.

\begin{tabular}{|c|c|c|c|c|}
\hline \multirow{2}{*}{ Procedure type } & Independent & Supervised & Assisted & Total \\
\hline & Mean, $95 \% \mathrm{Cl}$ & Mean, $95 \% \mathrm{Cl}$ & Mean, $95 \% \mathrm{Cl}$ & Mean, $95 \% \mathrm{Cl}$ \\
\hline All procedures & $511,413-610$ & $514,360-668$ & $752,485-1019$ & $1799,1335-2263$ \\
\hline Cranial procedures & $280,223-336$ & $264,202-326$ & $381,255-507$ & $938,731-1145$ \\
\hline Spinal procedures & $204,149-259$ & $246,123-368$ & $366,213-519$ & $835,529-1142$ \\
\hline $\begin{array}{ll}\text { Procedures } & \text { on } \\
\text { adult patients } & \end{array}$ & $466,371-562$ & $472,336-608$ & $696,448-945$ & $1661,1243-2079$ \\
\hline $\begin{array}{l}\text { Procedures on } \\
\text { pediatric patients }\end{array}$ & $35,20-50$ & $44,15-73$ & $78,20-137$ & $159,57-260$ \\
\hline
\end{tabular}


Table 3: Overview on the caseloads of specific types of procedures, performed on average during neurosurgery residency in Europe. $\mathrm{Cl}=$ confidence interval.

\begin{tabular}{|l|c|c|c|c|}
\hline \multicolumn{1}{|c|}{ Procedure type } & Independent & Supervised & Assisted & Total \\
\cline { 2 - 5 } & Mean, 95\% Cl & Mean, 95\% Cl & Mean, 95\% Cl & Mean, 95\% Cl \\
\hline Burr hole trepanation & $151,109-192$ & $82,11-152$ & $38,23-54$ & $270,145-396$ \\
\hline Supratentorial craniotomy & $118,89-147$ & $116,91-141$ & $148,111-185$ & $386,305-468$ \\
\hline Infratentorial craniotomy & $21,14-28$ & $30,21-39$ & $53,33-73$ & $107,73-140$ \\
\hline $\begin{array}{l}\text { Microsurgical treatment of } \\
\text { vascular pathology }\end{array}$ & $5,1-10$ & $13,6-19$ & $68,45-92$ & $88,60-117$ \\
\hline Endovascular procedure & $0,0-1$ & $1,-1-3$ & $2,1-3$ & $3,1-5$ \\
\hline Ventriculo-peritoneal shunt & $52,39-65$ & $28,20-36$ & $32,24-40$ & $109,87-132$ \\
\hline Neuro-endoscopic procedure & $4,2-6$ & $7,4-10$ & $10,7-13$ & $21,14-28$ \\
\hline Trans-sphenoidal procedure & $4,0-9$ & $7,4-10$ & $29,12-46$ & $38,18-58$ \\
\hline $\begin{array}{l}\text { Dorsal non-instrumented } \\
\text { spine surgery }\end{array}$ & $89,55-124$ & $82,46-118$ & $175,93-257$ & $350,196-504$ \\
\hline $\begin{array}{l}\text { Anterior instrumented or non- } \\
\text { instrumented spine surgery }\end{array}$ & $19,11-26$ & $24,16-33$ & $60,40-80$ & $104,69-139$ \\
\hline $\begin{array}{l}\text { Dorsal/lateral instrumented } \\
\text { spine surgery }\end{array}$ & $9,3-15$ & $22,11-33$ & $46,12-81$ & $77,27-127$ \\
\hline Cement augmentation & $2,1-3$ & $2,1-4$ & $3,2-5$ & $8,4-11$ \\
\hline Functional procedure & $24,15-34$ & $18,12-23$ & $35,16-53$ & $72,44-100$ \\
\hline Peripheral nerve procedure & $25,9-42$ & $10,4-16$ & $15,6-24$ & $53,24-82$ \\
\hline Stereotactic radiosurgery & $0,0-1$ & $1,0-3$ & $8,0-15$ & $9,0-18$ \\
\hline Cranioplasty & $14,10-17$ & $11,9-14$ & $13,10-17$ & $38,30-46$ \\
\hline
\end{tabular}




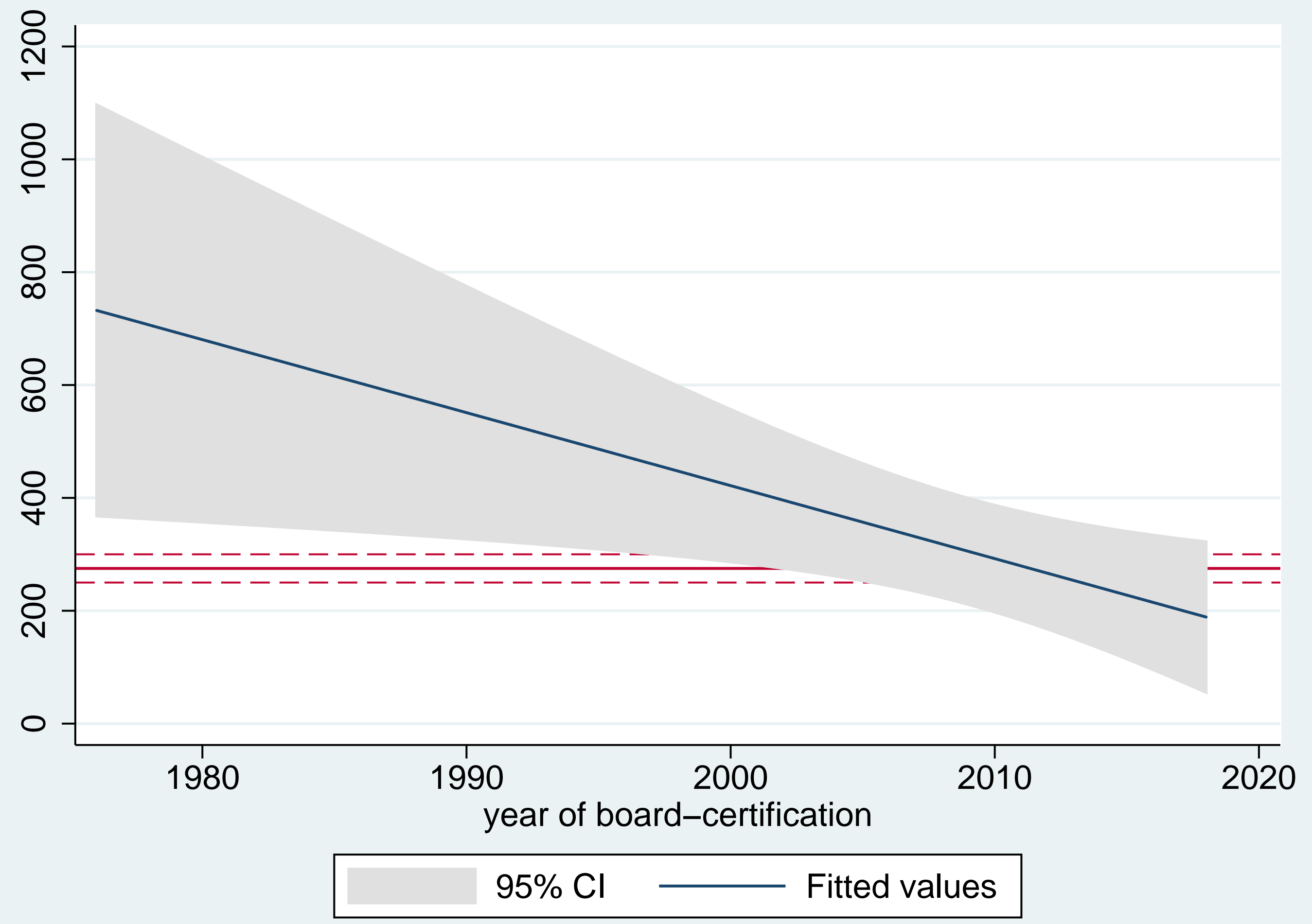




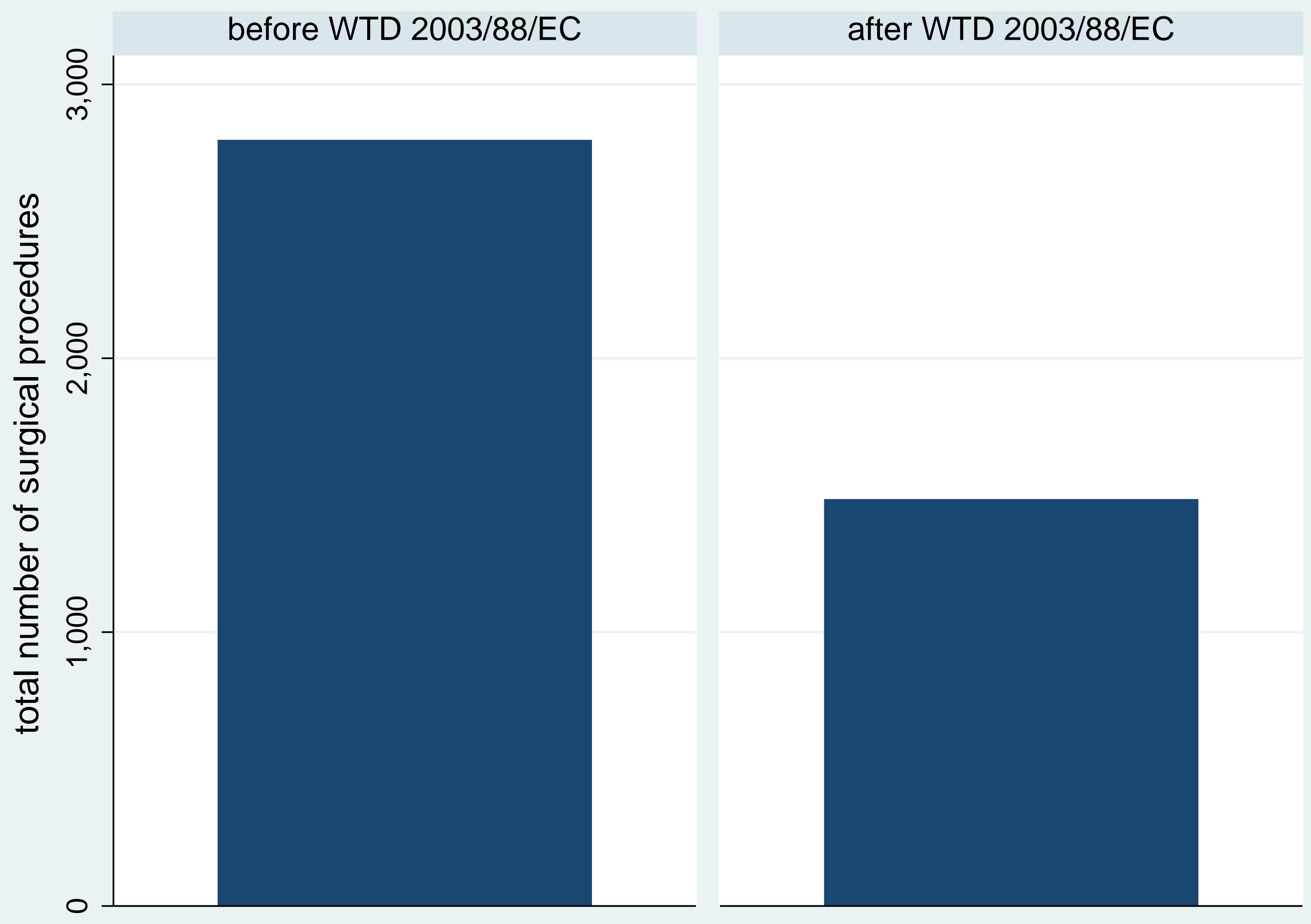




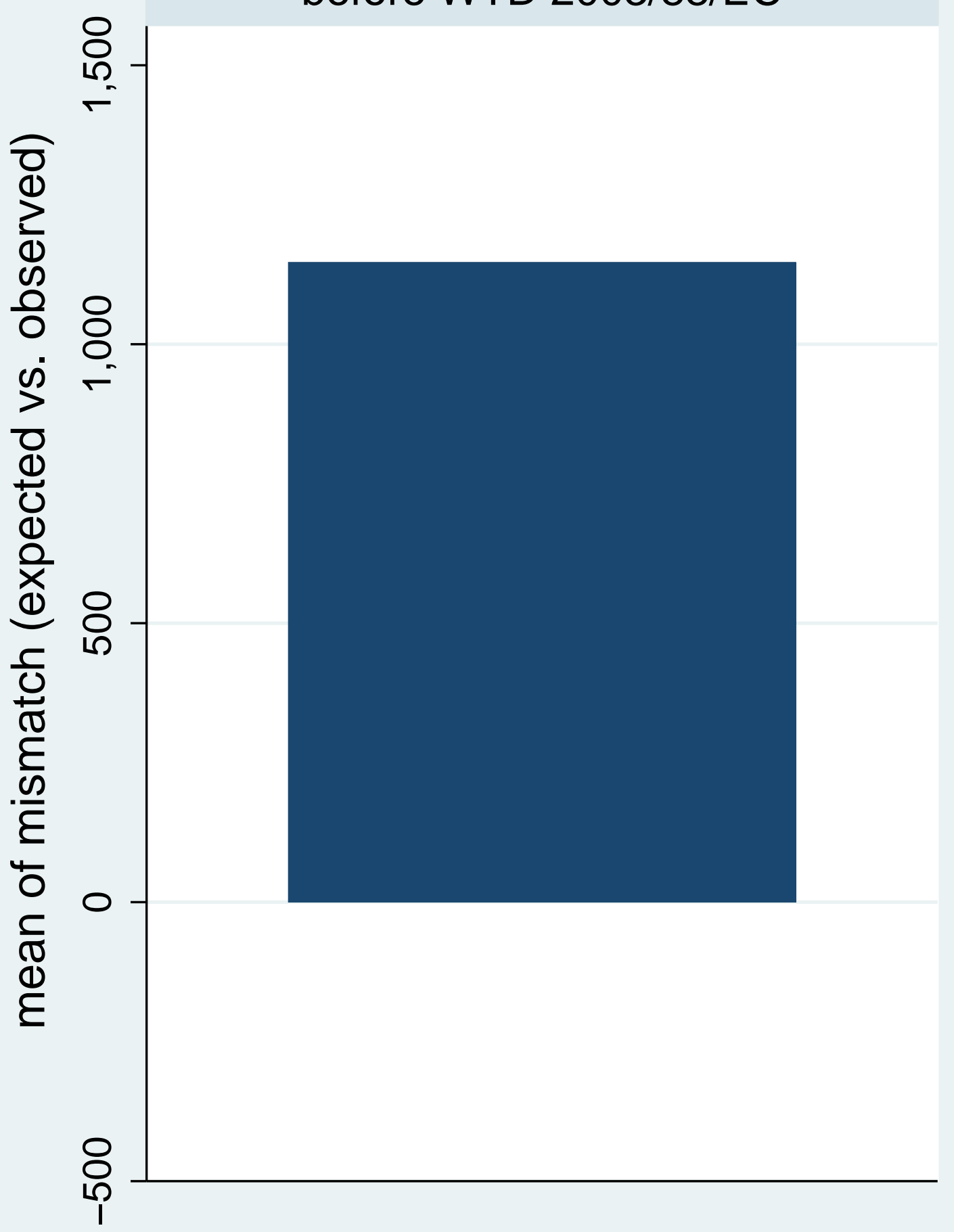




\section{Neurosurgical Procedures Performed During Residency in Europe - Preliminary Numbers and Time Trends}

Martin N. Stienen ${ }^{1,2}$, MD/FEBNS; Jiri Bartek Jr. ${ }^{3,4}$, MD; Marcus A. Czabanka5 , MD; Christian F. Freyschlag 6 , MD; Angelos Kolias ${ }^{7}, \mathrm{MD}$; Sandro M. Krieg ${ }^{8}, \mathrm{MD}$; Wouter Moojen ${ }^{9}, \mathrm{MD}$; Mirjam Renovanz ${ }^{10}$, MD; Nicolas Sampron ${ }^{11}$, MD/PhD; Sasan D. Adib ${ }^{10}$, MD; Gerrit A. Schubert $^{12}$, MD; Andreas K. Demetriades ${ }^{13}$, FRCS/FEBNS; Florian Ringel ${ }^{14}$, MD; Luca Regli $^{1,2}$, MD; Karl Schaller ${ }^{15}$, MD; Torstein R. Meling ${ }^{15}$, MD/PhD/FEBNS for the EANS Young Neurosurgeons and EANS Training Committee*

${ }^{1}$ Department of Neurosurgery, University Hospital Zurich, Zurich, Switzerland ${ }^{2}$ Clinical Neuroscience Center, University of Zurich, Zurich, Switzerland

${ }^{3}$ Department of Clinical Neuroscience and Medicine, Karolinska Institutet, Stockholm, Sweden

${ }^{4}$ Department of Neurosurgery, Rigshospitalet, Copenhagen, Denmark

${ }^{5}$ Department of Neurosurgery, Charité University Hospital, Berlin, Germany

${ }^{6}$ Department of Neurosurgery, Medical University of Innsbruck, Innsbruck, Austria

${ }^{7}$ Department of Clinical Neurosciences, University of Cambridge, Cambridge Biomedical

Campus, Cambridge, CB2 0QQ, United Kingdom

${ }^{8}$ Department of Neurosurgery, Klinikum rechts der Isar, Technical University Munich, Munich, Germany

${ }^{9}$ HAGA Teaching Hospital and Medical Center Haaglanden, The Hague \& Leiden University

Medical Center, Leiden, Netherlands

${ }^{10}$ Department of Neurosurgery, University Hospital Tübingen, Tübingen, Germany

${ }^{11}$ Servicio de Neurocirugía, Hospital Universitario Donostia, San Sebastián, Guipúzcoa, España

${ }^{12}$ Department of Neurosurgery, RWTH Aachen University, Aachen, Germany

${ }^{13}$ Department of Neurosurgery, Western General Hospital, Edinburgh, United Kingdom

${ }^{14}$ Department of Neurosurgery, University Medical Center, Johannes Gutenberg University

Mainz, Mainz, Germany

${ }^{15}$ Neurosurgery Division, Department of Clinical Neurosciences, Faculty of Medicine, Geneva University Hospitals, Geneva, Switzerland

${ }^{*}$ Members listed in the appendix

\section{Correspondence to:}

Martin N. Stienen, MD

Fellow of the European Board of Neurological Surgeons (FEBNS)

University Hospital Zurich 
Clinical Neuroscience Center

University of Zurich

Frauenklinikstrasse 10

8091 Zurich, Switzerland

Tel: +41-(0)44-255-1111

Email: mnstienen@gmail.com 


\section{Abstract}

Background: Differences in the postgraduate training programs of neurosurgical residents are suspected throughout Europe. The influence of working hour restrictions by the European Working Time Directive (WTD) 2003/88/EC on the number of surgical procedures remains unclear. We designed a survey to collect information on the number of surgical procedures, performed by European neurosurgical trainees during residency. This article reports preliminary data.

Methods: An electronic survey was distributed among the European Association of Neurosurgical Societies (EANS) member countries by national delegates of the training committee, as well as by members of the young neurosurgeons committee. The EANS mailing list of individual members was also used for distribution. All responses received between 04/2018 and 12/2018 were considered.

Results: From $n=180$ responses received, 42 were omitted as responders were still in residency and for 58 relevant information was missing. The final sample was $n=80$, with a mean responder's age of 43.0 years (SD 8.6 ) and $88.8 \%$ being male. Responses came from 16 European countries; board certification was received between the years of 1976-2018. The numbers of surgical procedures performed independently were 511 (mean, 95\% confidence interval (CI) 413-610), supervised were 514 (95\%CI 360-668) and assisted were 752 (95\% Cl 485-1019) throughout residency. More detailed numbers for specific procedure types are reported in the article. Independently performed cranial procedures outnumbered spinal procedures $(p<0.006)$ and adult procedures outnumbered pediatric procedures $(p<0.001)$. There was a strong decrease in case-load between 1976-2018, with trainees performing on average 65 cases less throughout residency for each calendar year increase in board-certification (95\% Cl $-116--15, p=0.012)$. Trainees graduating residency before introduction of the European WTD 2003/88/EC participated in more procedures than those graduating afterwards (mean 2797 vs. 1418, $p=0.005$ ).

Conclusions: The preliminary analysis of the first 80 responses now provides a first reference frame for case-load that can be used by current and future European residents to critically compare their own operative numbers to. There was a strong decline in surgical cases over time, and trainees graduating after introduction of the European WTD 2003/88/EC had less surgical exposure. The survey remains open and we invite further European neurosurgeons to provide their data in order to get even more robust estimates.

Key words: Neurosurgery; residency; caseload; Europe; training program; working hour restriction. 


\section{Abbreviations and Acronyms}

$\mathrm{Cl}=$ confidence interval

EANS $=$ European Association of Neurosurgical Societies

$\mathrm{h}=$ hours

JRAAC = Joint Residency Advisory and Accreditation Committee

$\mathrm{OR}=$ operation room

$S D=$ standard deviation

UK = United Kingdom

US $=$ United States (of America)

$\mathrm{VP}=$ ventriculo-peritoneal

WTD $=$ working time directive 


\section{Introduction}

Training the future generations of neurosurgeons is an important task that has lately received increasing attention, as conditions for European neurosurgeons have markedly changed over the last decades and a direct relationship between the perceived quality of training and actual knowledge \& skills level in the European board examination of neurosurgery could be established.[21] There has been a transition from traditional, individualized and more liberal surgical training models with Halsted's "see one, do one, teach one" mentality to the progressive establishment of standardized programs.[1] A multitude of positive developments have occurred, including the introduction of structured residency curriculums, their accreditation and monitoring by the Joint Residency Advisory and Accreditation Committee (JRAAC),[18] the increasing availability of (inter-)national training courses, simulators \& modern e-learning techniques for postgraduate training.[13, 15, 23, 28] Besides, improvements in professional networking and exchange by events such as the European Associations of Neurosurgical Societies (EANS) Training Courses or Young Neurosurgeon's meetings have taken place, enabling trainees to gain a profound knowledge on theoretical aspects of neurosurgical care.

Despite a wealth of academic training possibilities, the practical "hands-on" experience level of today's residents seems to decline, however, compared to the one of previous generations. This reduction may result from several reasons, among them the instituted 48-hour work week and duty hour restrictions as defined by the European Working Time Directive (WTD) 2003/88/EC,[17, 22] with the subsequent increase of the number of trainees and hereby broader distribution of a department's surgical cases,[22] but also from the increase in competition on the so-called "health-care market" with a zero-tolerance attitude for complications and suboptimal outcomes today, hindering resident participation in key aspects of cases.[4, 24] Reulen \& März, in a thoughtful article on the training conditions at a major German neurosurgical department, estimated that an annual case-load of 250-300 procedures per resident would be needed for adequate training are met - but it is unclear, whether European trainees meet those expectations.[16]

European neurosurgery residents express an uncertainty with regards to the definition of a "normal volume of procedures" that their peers perform independently, supervised or assisted throughout training. In order to provide some transparency and reference values, we surveyed European board-certified neurosurgeons and asked them to indicate the case numbers performed throughout training. Further intentions were to analyze time-trends in surgical case loads - in particular comparing case numbers performed by residency graduates before and after the WTD 2003/88/EC was introduced - and to estimate their effect on training. 


\section{Material and Methods}

Survey design

An electronic survey consisting of 31 questions on four pages was created using the survey tool "Survey Monkey" (SurveyMonkey Inc., San Mateo, California (USA), https://www.surveymonkey.com). Questions covered basic demographic data about the survey responder including age, sex, country of training, additional out-of-country training, as well as year of board-certification in neurosurgery.

Responders were then asked to indicate the amount of surgical procedures performed independently, performed under supervision, or assisted throughout their residency (until board-certification). We collected data on all operative cases, but also discriminated between a) total cranial cases, b) total spinal cases, c) total adult cases, d) total pediatric cases (age 0-16 years).

In a further section, responders were asked to indicate their case numbers for specific neurosurgical procedures, again separately for those performed independently, performed under supervision, or assisted: a) burr hole trepanation, b) supratentorial craniotomy, c) infratentorial craniotomy, d) microsurgical treatment of vascular pathology, e) endovascular procedure, f) ventriculo-peritoneal (VP)-shunt, g) neuro-endoscopic procedure, h) transsphenoidal procedure, i) dorsal non-instrumented spine surgery, j) anterior instrumented or non-instrumented spine surgery, k) dorsal/lateral instrumented spine surgery, I) cement augmentation, $m$ ) functional procedure, $n$ ) peripheral nerve procedure, o) stereotactic radiosurgery, $p$ ) cranioplasty. The final question assessed, whether the provided numbers were based on actual records or "best estimates".

In general, survey questions were constructed carefully to avoid influencing the answers and the complete survey is provided as Supplemental File 1 so that the reader can decide whether the questions were reasonable.

\section{Survey distribution}

The survey was distributed twice via the EANS mailing list to individual members. Furthermore, all national delegates of the EANS were asked to forward the survey link among members of their national neurosurgical societies. In addition, members of the EANS Young Neurosurgeons and Training Committee were asked to forward the link among their colleagues and professional networks. Personal email-based invitations were used; no social-media platform advertisement was used. Multiple answering of the survey using the same IP address was impossible. No reminder emails were sent in case of non-response, to respect the decision of non-participation. Questionnaires of all responders between April $25^{\text {th }}$, 2018 and until December $31^{\text {st }}, 2018$ were included in this preliminary analysis. 


\section{Statistical considerations}

Continuous variables were reported as mean and $95 \%$ confidence intervals (Cl); t-tests were used for statistical analysis. Frequency distributions and summary statistics were calculated for categorical variables; chi-square tests served for statistical analysis.

Descriptive statistics were used to present the mean case-loads and $95 \% \mathrm{Cls}$ for certain procedure types. General time trends in the case-load were analyzed using linear regression. In order to determine the change in case-load specifically before and after introduction of the European WTD 2003/88/EC, we dichotomized between surgeons who graduated residency up to year 2004, or from 2005 onwards and compared case-loads using $\mathrm{t}$-tests. To estimate the magnitude of deviation from a target case-load, we used the annual number of $250-300$ major procedures per resident that was previously suggested to ensure adequate surgical exposure, with resident participation in about $40-45 \%$ of cases (expert opinion).[16] As the survey included major and minor procedures, and recorded procedures where trainees were assisting an attending, we used the annual $250-300$ case threshold as reference. Based on the length of residency (as indicated by survey responders), the mean target case-load of residency would range around 1704 (95\% Cl 1610 - 1799). This number was used to calculate the mismatch between expected (=desired) and observed (=actual) residency case-load.

The software used for the statistical analysis and graphical illustration was Stata v14.2 (StataCorp LP, College Station, TX, USA). P-values $<0.05$ were considered statistically significant.

\section{Ethical considerations}

Survey participation was voluntary. No patient data was collected. Formal consent was not required for this type of study.

\section{Results}

Until December $31^{\text {st }}$, 2018 we received a total of 180 responses, of which 42 were excluded because responders indicated not having completed their training yet, and a further 58 responses due to incomplete and missing relevant data. Therefore, $n=80$ responses were considered for this preliminary analysis.

Details on the survey sample are summarized in Table 1. Survey responders had a mean age of $43.0 \pm 8.6$ years and $88.8 \%$ were male. Responses mainly came from surgeons employed at university/teaching hospitals (91.3\%) in France (20.0\%), the United Kingdom (UK; 13.8\%), Germany (15.0\%\%), Switzerland (11.3\%), Serbia and Norway (each 8.8\%). Most responders graduated in the years between 2011 - 2018 (57.5\%). Nineteen responders 
(23.8\%) graduated before and 61 responders (76.2\%) after the European WTD 2003/88/EC came into effect. The mean duration of residency was $6.1 \pm 1.4$ years.

\section{Absolute numbers of procedures in general}

The mean number of surgical procedures performed independently, supervised or assisted throughout residency was 511 (95\% Cl: 413-610), 514 (95\% Cl: 360-668) and 752 (95\% Cl: 485-1019). The relatively wide $95 \% \mathrm{Cls}$ indicate substantial inter-individual heterogeneity. Detailed numbers for cranial, spinal, adult, and pediatric subgroups are presented in Table 2.

In general, European trainees had more exposure to independently performed cranial as compared to spinal operations ( $280 \pm 251$ vs. $204 \pm 245, p=0.006)$. Exposure to cranial and spinal operations was similar for supervised (264 \pm 262 vs. $245 \pm 516, p=0.631$ ) and assisted procedures ( $381 \pm 538$ vs. $366 \pm 651, p=0.621$ ).

Trainees were much more exposed to adult, as compared to pediatric procedures, including those performed independently (472 \pm 412 vs. $35 \pm 65, p<0.001$ ), supervised (472 \pm 572 vs. $44 \pm 121, p<0.001$ ) or assisted (705 \pm 1048 vs. $78 \pm 243, p<0.001$ ).

\section{Absolute numbers of specific neurosurgical procedures}

Table 3 summarized mean numbers of specific neurosurgical interventions, again discriminated between those performed independently, supervised, or assisted throughout residency. With an average of 151 procedures, burr-hole trepanation was the procedure that was most frequently performed independently. Based on the responses of this survey, we are 95\% confident that European residents perform between 109 and 192 such procedures independently throughout residency (Table 3). Further procedures performed relatively often were supratentorial craniotomies (average 118, 95\% Cl: 89-147), dorsal non-instrumented spine procedures (average 89, 95\% Cl: 55-124) and VP-shunts (average 52, 95\% Cl: 3965 ). At the lower end of the spectrum, only few stereotactic radiosurgery (average $0,95 \% \mathrm{Cl}$ : 0-1), endovascular (average 0,95\% Cl: 0-1), cement augmentation (average 2, 95\% Cl: 13) or trans-sphenoidal (average 4, 95\% Cl: 0-9) procedures were performed (Table 3).

For the more simple and less dangerous procedures (e.g. burr hole trepanation, VPshunt, peripheral nerve procedure, cranioplasty), more procedures were performed independently than supervised or assisted. In contrast, most numbers for assists or supervised exceeded those of independently performed procedures, if degree of complexity or risk of morbidity was higher (e.g. infratentorial craniotomy, vascular procedure, transsphenoidal procedure, dorsal/lateral instrumented spine procedure; Table 3).

Trend of residency case-load over time 
We analyzed, whether the residency case-load changed over time. In a linear regression model, there was an annual decrease in total case-load of about 65 cases between 19762018 (Coeff. $-65,95 \% \mathrm{Cl}-116--15, \mathrm{p}=0.012$ ). Also, the number of procedures performed per residency year (=case-year index) between 1976-2018 showed a decrease with about 13 cases less per year (Coeff. $-13,95 \% \mathrm{Cl}-24--2, p=0.018$ ). Figure 1 illustrates the decrease in mean annual caseload/resident over time, with the red lines indicating the suggested threshold for adequate training of $250-300$ (mean: 275) cases/year.

When dichotomized for the time before or after introduction of the European WTD 2003/88/EC, the total residency case-loads were higher before as compared to after (2797 \pm 3607 vs. $1418 \pm 865, p=0.005$; Figure $2 A$ ). While the difference between expected and observed case-load was positive before introduction of the European WTD 2003/88/EC, it was negative afterwards ( $1147 \pm 3704$ vs. $-285 \pm 837, p=0.004$; Figure $2 B$ ). The results were consistent when analyzing the number of procedures performed per residency year (=caseyear index; $521 \pm 787$ (before) vs. $221 \pm 124$ (after), $p=0.003$ ).

\section{Discussion}

This survey set out to explore how many procedures European neurosurgical trainees perform throughout residency. Here, we provide first numbers that enable current and future trainees to compare their own surgical exposure with the European average and to react, if their numbers are insufficient. Furthermore, our results substantiate ongoing speculations about a decrease in case-load over time with actual data: we found a strong decline of around 65 cases/year between $1976-2018$ and the drop in case-load was significant after introduction of the European WTD 2003/88/EC. Particularly striking was the finding that before introduction of the European WTD 2003/88/EC, the previously proposed aim of 250300 procedures per year per resident was by far exceeded, while it was not reached anymore afterwards.

The motivation to conduct this survey primarily derived from discussions with trainees at multiple EANS events over the last years. Here, significant inter-individual differences in the number of surgical procedures and the degree of responsibility emerged. However, it remained unclear how many cases would be "normal" among the peer group of trainees. Moreover, in a prior survey we had noticed a relatively low confidence level of European residents when entering the life of responsibility as attending neurosurgeons, which resulted from a perceived deficit in hands-on operative experience.[5] To the question whether residents felt well-prepared to work on their own responsibility after residency, only 75 of 452 responders (16.6\%) answered "yes, surely", whereas $100(22.1 \%)$ answered "yes, if surgical exposure improved", 16 (3.5\%) answered "yes, if theoretical training improved", $120(26.6 \%)$ 
answered "yes, if both improved". More than one-third indicated not feeling enough prepared, mostly due to lack of hands-on operative training $(100 ; 22.1 \%)$, less so for too little theoretical knowledge $(9 ; 2.0 \%)$, or both $(32 ; 7.1 \%)$.[5] Todays options with regards to theoretical training are abundant, with the increasing number of EANS courses, availability of e-learning platforms, and e-content on the EANS academy, besides further options on a local or national level or provided by the industry.[5, 23] Thus, it emerged to us that especially the practical aspects of neurosurgery training appear to offer room for further improvement, which is why this was focused on here.

\section{Self-assessment of residency case-load}

The information contained in Tables $2 \& 3$ enable each current or future neurosurgical resident to critically evaluate his/her individual training situation and ranking within his/her peer group of European co-residents. It points out the average number of each kind of surgical procedure with confidence intervals, indicating the range in which case numbers of $95 \%$ of responders from Europe fall, until the end of their residency. The practical application of this is evident: should an individual neurosurgical resident realize that he/she falls below this reference frame on any of the categories - meaning that his/her hands-on training in this particular field is inferior to the training of his/her European peers - he/she should discuss this shortcoming with his/her chairperson and find ways to compensate for this deficiency, e.g. by a rotation to a different hospital or by organizing a dedicated fellowship. On the contrary, the tables can also help to identify particular strengths of each resident's training program in terms of "hands-on experience". For example, a typical European neurosurgical trainee should have participated on 30-46 cranioplasty procedures until the end of residency (mean 38), assisting 10-17 (mean 13), performing between 9-14 under supervision (mean of 11) and 10-17 independently (mean 14). The numbers reported in the table - despite the limited number of responses so far - compare well with our personal experience, lending credibility to the results.

Despite the power that lies in this data, some words of caution are required, too. First, case-load estimations base on a survey sample and we have no means of controlling how correct they are. Second, every hospital has a certain focus, and while lagging behind in one aspect of neurosurgery, the same trainee might outperform his/her peers in a different field with particular local expertise. Falling below average on a single item therefore is not equal to unfavorable training conditions in general. Lastly, the numbers provided in Tables $2 \& 3$ are averages calculated across all years, but there is a decrease in surgical case-loads over time during residency (Figures $1 \& 2$ ). As the survey hopefully receives more responses in the future, this would enable us to calculate specific reference values for the current decade, as 
well as tighter confidence intervals for those categories that still have a wide spread of data for now.

\section{Time trends in case-load}

There was a decrease in surgical case-load over the period from 1976-2018 that our survey spans and the majority of European neurosurgical trainees today do not participate in the recommended number of operations per year (Figure 1). Such a development has been expected, and it is typically attributed to the government-enforced restriction in working time. Correspondingly, our data indeed indicate a significant association between the introduction of the WTD and a lower case-load (Figure 2A\&B).

Restrictions of maximum working time were introduced for the best of intentions in Europe and the United States (US), but are often criticized to interfere with the inevitably long and intense neurosurgical training. In a survey among US neurosurgery residents and program directors around two years after introduction of an $80 \mathrm{~h} /$ week restriction (besides other regulations), the perceptions suggested that neurosurgery training was negatively affected by around $60 \%$ of residents and $80 \%$ of program directors.[2] In the same study, $60 \%$ of residents felt that their exposure to complex cases was decreasing. When we previously surveyed a sample of $n=458$ European neurosurgery residents about their opinion on the working hour restrictions to $48 \mathrm{~h} /$ week by the European WTD 2003/88/EC - also roughly two years after its introduction - about a third (29\%) indicated being satisfied, $11.4 \%$ preferred to reduce working time even more, and $4.6 \%$ had no opinion. More than half $(55 \%)$, however, indicated their preference to work more hours/week, provided this time was spent to enhance their clinical/surgical education (operation room (OR) exposure) and not used for administrative work.[22] Subgroup analyses identified those responders to desire more working time that regarded their hands-on surgical training insufficient, who felt unable to take over responsibility yet, and who expressed sorrows regarding future career options (all $\mathrm{p}<0.009$ ).[22] The preference of many to work more could therefore be interpreted as a reaction towards insufficient hands-on OR exposure.

It is evident that opinions vary with regards to working time, but the large proportion of residents that would be willing to work even longer hours also indicates a devotion to the specialty of neurosurgery. European trainees seem to realize that in this extremely sensitive profession, extraordinary experience and high competence to ensure safe patient care can only be attained and maintained by sacrifice of time. In addition, residents may have understood that attempts to mandate a "shift-worker" mentality run contrary to the complex and unpredictable nature of neurological illnesses.

It remains unclear from this work, however, whether the decrease in case-load can be attributed solely to the restrictions in working time. In particular, our previous survey identified 
poor compliance with the $48 \mathrm{~h}$ workweek by only $37.6 \%$ of European residents.[22] Other reasons may factor into this result, including the subsequent increase in number of residents per department [16] - that may also be an indirect result of the WTD - but also the loss of traditionally "surgical candidates" to modern non-surgical therapeutic alternatives (e.g., by advances in radio-, chemo- and/or immunotherapy in neuro-oncology, endovascular treatment for cerebrovascular pathologies, decreasing incidence \& prevalence of neurological diseases by change in lifestyle and primary prophylaxis etc.). Besides operational efficiency \& economic goals that are increasingly imposed on attending surgeons even in dedicated teaching hospitals, private hospitals additionally compete for operative cases in most regions within an increasingly vying health-care market,[24] which negatively affects surgical training. Last but not least, junior attending surgeons, who graduated after introduction of the WTD, are now increasingly employed at teaching hospitals. They try to gain substantial operative experience during their first years of practice in order to compensate for the lower case-loads during their own residencies, further negatively impacting the training of their residents. These developments have provided disincentives for attending surgeons to grant residents increased roles in care. Whether the implementation of modern technologies in the OR, such as e.g., neuronavigation, intraoperative magnetic resonance imaging or preoperative case-specific 3D-printing, might be able to partially compensate for the smaller case-loads - as didactics of surgical planning is improved - is yet to be proven. However, the convergence of named factors has altered the landscape of neurosurgery training.

\section{How to improve surgical training}

This article intends to stir some thought processes on how to maintain neurosurgical training at a high level while maintaining patient care. The current development with lesser cases per resident per year points towards a limited number of possible solutions.

First, operative involvement of residents could happen at an earlier time during training than today, according to a "fast-track Halstedian model" where residents are gradually entrusted with increasing responsibility from day 1 of residency onward. A proper preparation would seem necessary, however, possibly starting to subspecialize some medical students into surgery already at the University level and provide them with ample general surgical skills before starting neurosurgical residency, e.g. by "neurosurgical bootcamps". A steady progression and close monitoring and mentorship would be required to ensure development of expert technical skills over a relatively short mean residency-period of six years. Theoretical and simulator-based training sessions can pave the way and there is some evidence that simulation-courses can improve both knowledge and skills in areas that typically fall short in residency, such as suturing micro-anastomoses, etc. [28] Still, surgical 
maturation essentially requires comprehensive involvement in the "real-world" OR environment, too. A number of recent publications indicate that for a large variety of procedures early resident involvement - under supervision - does not come at the cost of higher complications or worse patient outcomes.[6-11, 14, 20, 25-27] According to our personal experience, US and UK residents participate in the OR to a greater extent than many other European sites and recent data underpins this: a study conducted in Boston showed that resident involvement in general surgery was substantial, performing the majority of important surgical steps (range: $86 \%-97 \%$ ), including opening, dissection of minor and major anatomical structures, major suturing, incision closure.[12] An increasing tendency of European trainees to participate in international exchanges and fellowships may support a gradual change in the traditional European mind-set where the concept of "see one, do one, teach one" is more distorted with residents frequently observing master surgeons elegantly performing surgery, but having little opportunity to develop own manual dexterity.

Second, residency could be prolonged in order to account for the decline in surgical cases per year. Similar to the UK model, other European countries might upgrade their residency time from 5-6 years to 7-8 years. This model was not preferred by $n=532$ European trainees, however, as most (45.5\%) considered residency length sufficient if more time was spent with practical neurosurgery (and less so with administrative/paper work). Further $18.1 \%$ voted against a residency prolongation for its recoiling effect on students to sign up for neurosurgery training, among other reasons. Only $17.5 \%$ were in favor of residency prolongation.[22]

A third option could be the progressive introduction of fellowship training in Europe where - similar to the US model - the aim of residency is to gain basic skills on the broad field of neurosurgery, with sub-specialization afterwards by dedicated fellowships. The latter is typically conducted in one or two specific areas of expertise that are later covered during the professional career. Again, data from the US show that in vascular surgery - a surgical field that competes similarly with the rise of endovascular treatment options - dedicated programs where cases are concentrated allow fellows to acquire sufficient case-loads.[3] Option three is similar to option two. However, it is more appealing to residents, as they are promoted in status. In addition, with international applications for fellowship positions, such a model would strengthen exchange and collaboration on a European and global scale.

\section{Strengths and Limitations}

This survey is the first of its kind to collect information on actual surgical case-loads throughout Europe. Despite considerable efforts to distribute the survey using multiple channels over the course of eight months, we have - so far - received a relatively limited number of 180 responses, of which only 80 could be included in the analysis. This may be 
due to the fact that it takes some effort for responders to look up the exact case numbers in 
The preliminary analysis of the first 80 responses now provides a first reference frame for case-load that can be used by current and future residents to critically compare their own operative numbers to. There was a strong decline in surgical cases over time, and trainees graduating after introduction of the European WTD 2003/88/EC had less surgical exposure. The survey remains open under https://www.surveymonkey.com/r/RJMSLCG and we invite further European neurosurgeons to provide their data in order to get even more robust estimates. 


\section{Figure legends}

Figure 1: Linear predictions plot with $95 \%$ confidence intervals $(\mathrm{Cl})$, illustrating time trends ( $x$-axis: year of residency graduation) in annual case-load ( $y$-axis: number of procedures/year) for European neurosurgical residents. The fitted line indicates a decrease in case-load over time. In a linear regression model, there was an annual decrease of about 13 cases (Coeff. $-13,95 \% \mathrm{Cl}-24--2, p=0.018$ ). The red reference lines indicates the proposed threshold for adequate surgical training, ranging around 275 (250-300) per year and resident.[16]

Figure 2: Bar charts. A) Illustration of the mean total number of surgical procedures ( $y$-axis) performed throughout residency before and after introduction of the European Working Time Directive (WTD) 2003/88/EC (x-axis). It was higher before as compared to after introduction of the WTD 2003/88/EC (2797 vs. 1418, $p=0.005$ ). B): Illustration of the mismatch between expected vs. observed mean total number of surgical procedures ( $y$-axis) performed throughout residency before and after introduction of the European Working Time Directive (WTD) 2003/88/EC (x-axis). It was positive before and negative after introduction of the WTD 2003/88/EC (1147 vs. $-285, p=0.004$ ). 


\section{Acknowledgements}

We want to acknowledge the substantial support that we have received from the EANS office with regards to generating, approving and distributing the survey, in particular Amy Pinchbeck-Smith, Petra Koubova, Liz Derow and Francesco Sala. We thank the EANS Young Neurosurgeons \& EANS Training Committee members for reviewing and revising the questionnaire, in particular those who also distributed the survey among their national societies. We thank Hans Clusmann, Pierre-Hugues Roche, Yerbol Makhambetov, Marcel Ivanov and Laszlo Novak for initiating its distribution among the Neurosurgical Societies in Germany, France, Kazakhstan, Great Britain, and Hungary, respectively.

\section{Survey}

The survey continues to be accessible under the following link: https://www.surveymonkey.com/r/RJMSLCG. We would like to invite neurosurgeons, who have finished their neurosurgical training in a European country (for the most part) to provide their surgical case numbers, using the link above. Please note that confidentiality of individual responses is provided. Responders may provide their data anonymously, but can choose to indicate their name for indexing purpose as contributor on publications that use survey data.

\section{Conflicts of Interest}

All authors certify that they have no affiliations with or involvement in any organization or entity with any financial interest (such as honoraria; educational grants; participation in speakers' bureaus; membership, employment, consultancies, stock ownership, or other equity interest; and expert testimony or patent-licensing arrangements), or non-financial interest (such as personal or professional relationships, affiliations, knowledge or beliefs) in the subject matter or materials discussed in this manuscript.

\section{Funding}

No funding was received for this research.

\section{Ethical approval}

For this type of study formal consent is not required.

\section{Informed consent}

Survey participation was voluntary. No patient data was collected. 


\section{APPENDIX}

Collaborators of the "EANS YNC and TC" (listed in alphabetical order):

- Sasan D. Adib

- Amro Al-Habib

- Rafid Al-Mahfoudh

- Ridvan Alimehmeti

- Aymeric Amelot

- Lisa Arvidsson

- Nurali Ashirov

- Toomas Asser

- Kaspar Auslands

- Cecilia I. A. Avellan

- Jiri Bartek Jr.

- Jacques Beaurain

- Luka Berilazic

- Roman Bosnjak

- Pierre Bourdillon

- Oliver Bozinov

- Anna Martina Brunner

- Bilginer Burcak

- Alexandre Carpentier

- Antonio Cerejo

- Hans Clusmann

- Dominik Cordier

- Marcus Czebanka

- Suparna Das

- Andreas Demetriades

- Sandra F. Dias

- Francesco DiMeco

- Djula Djilvesi

- Johnny Duerinck

- Chloé Dumot

- Pierre-Jacques Finiels

- Nikolaos Foroglou

- Christian F. Freyschlag

- Arnab Ghosh

- Dimitrios Giakoumettis 
- Nathalie Gilis

- Jagos Golubovic

- Stefan J. Grau

- Nils Hecht

- Markus Holling

- Bogdan Iliescu

- Marcel Ivanov

- Timothee Jacquesson

- Dariusz Jakolski

- Ibrahim Jalloh

- Assylbek Kaliyev

- Almuth F. Kessler

- Jean-Charles Kleiber

- Angelos Kolias

- Nikolay Konovalov

- Karl F. Kothbauer

- Vojin Kovacevic

- Nenad Krajcinovic

- Sandro M. Krieg

- Aki Laakso

- Christophe Lapras

- Aaron Lawson McLean

- Caroline Le Guerinel

- Milan Lepic

- Dominique Liguoro

- Johan Ljungqvist

- William B. Lo

- Ivan Macuga

- Martin Majovsky

- Yerbol Makhambetov

- Francesco Marchi

- Torstein R. Meling

- Anthony Melot

- Antonio Meola

- Patrick Mertens

- Stephen Metcalfe

- Svein Harald Moerkve 
- Wouter Moojen

- Arsim Morina

- Mohammad Jawad Naushahi

- Laszio Novak

- Aitimbetov Nurzhan

- Ibrahim Omerhodzic

- Johan Pallud

- Vakis Papanastassiou

- Vladimir Papic

- Michael Payer

- Jenny Pettersson Segerlind

- Jussi P. Posti

- Francois Proust

- Lukas Rasulic

- Luca Regli

- Michael Reinert

- Mirjam Renovanz

- Florian Ringel

- Jaako Rinne

- Pierre-Hugues Roche

- Saulius Rocka

- Roman Rotermund

- Scott A. Rutherford

- Tönu Rätsep

- Ilkka M. Saarenpää

- Marko Samardzic

- Nicolas Sampron

- Ulrika Sandvik

- Michel Schneider

- Gerrit Schubert

- Saurabh Sinha

- Jane Skjoeth-Rasmussen

- Volodymyr Smolanka

- Martin Smrcka

- Ole Solheim

- Sergey Spektor

- Martin N. Stienen 
- Mario Teo

- Claudius Thomé

- Simon Thomson

- Magnus Tisell

- Cristina P. Torres Diaz

- Dirk Van Roost

- Henk van Santbrink

- Nicolay Velinov

- Aleksic Vuk

- Miroslav Vukic

- James Walkden

- Christopher Wendel 


\section{References}

1. Burkhardt JK, Zinn PO, Bozinov O, Colen RR, Bertalanffy H, Kasper EM (2010) Neurosurgical education in Europe and the United States of America. Neurosurg Rev 33:409-417

2. Cohen-Gadol AA, Piepgras DG, Krishnamurthy S, Fessler RD (2005) Resident duty hours reform: results of a national survey of the program directors and residents in neurosurgery training programs. Neurosurgery 56:398-403; discussion 398-403

3. Cronenwett JL (2006) Vascular surgery training: is there enough case material? Semin Vasc Surg 19:187-190

4. Dafny LS, Lee TH (2016) Health Care Needs Real Competition. Harvard Business Review:76-87

5. Gautschi OP, Smoll NR, Corniola MV, Joswig H, Chau I, Hildebrandt G, Schaller K, Stienen MN (2016) Validity and Reliability of a Measurement of Objective Functional Impairment in Lumbar Degenerative Disc Disease: The Timed Up and Go (TUG) Test. Neurosurgery 79:270-278

6. Joswig H, Gautschi OP, El Rahal A, Sveikata L, Bartoli A, Hildebrandt G, Schaller K, Stienen MN (2016) Cranioplasty: Is Surgical Education Safe? World Neurosurg 91:81-88 7. Joswig H, Haile SR, Hildebrandt G, Stienen MN (2017) Residents' Learning Curve of Lumbar Transforaminal Epidural Steroid Injections. J Neurol Surg A Cent Eur Neurosurg 78:460-466

8. Joswig H, Hock C, Hildebrandt G, Schaller K, Stienen MN (2016) Microscopic lumbar spinal stenosis decompression: is surgical education safe? Acta Neurochir (Wien) 158:357-366

9. Joswig H, Jucker D, Lavalley A, Sprenger L, Gautschi OP, Hildebrandt G, Schaller K, Stienen MN (2017) Shunts: Is Surgical Education Safe? World Neurosurg 102:117-122

10. Kim RB, Garcia RM, Smith ZA, Dahdaleh NS (2016) Impact of Resident Participation on Outcomes After Single-Level Anterior Cervical Diskectomy and Fusion: An Analysis of 3265 Patients from the American College of Surgeons National Surgical Quality Improvement Program Database. Spine (Phila Pa 1976) 41:E289-296

11. Maldaner N, Sosnova M, Sarnthein J, Bozinov O, Regli L, Stienen MN (2018) Burr hole trepanation for chronic subdural hematomas: is surgical education safe? Acta Neurochir (Wien) 160:901-911

12. Morgan R, Kauffman DF, Doherty G, Sachs T (2017) Resident and attending assessments of operative involvement: Do we agree? Am J Surg 213:1178-1185 e1171

13. Nicolosi F, Rossini Z, Zaed I, Kolias AG, Fornari M, Servadei F (2018) Neurosurgical digital teaching in low-middle income countries: beyond the frontiers of traditional education. Neurosurg Focus 45:E17

14. Niimura M, Takai K, Taniguchi M (2017) Comparative study of perioperative complication rates of cervical laminoplasty performed by residents and teaching neurosurgeons. J Clin Neurosci 45:73-76

15. Perin A, Galbiati TF, Gambatesa E, Ayadi R, Orena EF, Cuomo V, Riker NI, Falsitta LV, Schembari S, Rizzo S, European Neurosurgery Simulation Study G, Luciano C, Cappabianca P, Meling TR, Schaller K, DiMeco F (2018) Filling the gap between the OR and virtual simulation: a European study on a basic neurosurgical procedure. Acta Neurochir (Wien) 160:2087-2097

16. Reulen HJ, Marz U (1998) 5 years' experience with a structured operative training programme for neurosurgical residents. Acta Neurochir (Wien) 140:1197-1203 17. Schaller K (2013) Neurosurgical training under European law. Acta Neurochir (Wien) 155:547 
18. Steers J, Reulen HJ, Lindsay KW, European Union of Medical S, Joint Residency A, Accreditation C (2004) UEMS charter on training of medical specialists in the EU--the new neurosurgical training charter. Acta Neurochir Suppl 90:3-11

19. Stienen MN, Gautschi OP, Schaller K, Netuka D, Demetriades AK, Ringel F, Gempt J, Kuhlen D (2016) Letter to the Editor: Training and career aspects of female neurosurgical residents in Europe. J Neurosurg 125:1317-1320

20. Stienen MN, Joswig H, Jucker D, Hildebrandt G, Schaller K, Gautschi OP (2015) Anterior cervical discectomy and fusion: is surgical education safe? Acta Neurochir (Wien) 157:1395-1404

21. Stienen MN, Netuka D, Demetriades AK, Ringel F, Gautschi OP, Gempt J, Kuhlen D, Schaller K (2016) Residency program trainee-satisfaction correlate with results of the European board examination in neurosurgery. Acta Neurochir (Wien) 158:1823-1830

22. Stienen MN, Netuka D, Demetriades AK, Ringel F, Gautschi OP, Gempt J, Kuhlen D, Schaller K (2016) Working time of neurosurgical residents in Europe--results of a multinational survey. Acta Neurochir (Wien) 158:17-25

23. Stienen MN, Schaller K, Cock H, Lisnic V, Regli L, Thomson S (2017) eLearning resources to supplement postgraduate neurosurgery training. Acta Neurochir (Wien) 159:325-337

24. Stienen MN, Serra C, Stieglitz LH, Krayenbuhl N, Bozinov O, Regli L (2018) UniversitatsSpital Zurich: 80 years of neurosurgical patient care in Switzerland. Acta Neurochir (Wien) 160:3-22

25. Stienen MN, Smoll NR, Hildebrandt G, Schaller K, Gautschi OP (2014) Early surgical education of residents is safe for microscopic lumbar disc surgery. Acta Neurochir (Wien) 156:1205-1214

26. Stienen MN, Smoll NR, Tessitore E, Schaller K, Hildebrandt G, Gautschi OP (2015) Surgical Resident Education in Noninstrumented Lumbar Spine Surgery: A Prospective Observational Study with a 4.5-Year Follow-Up. World Neurosurg 84:1589-1597

27. Vasella F, Velz J, Neidert MC, Henzi S, Sarnthein J, Krayenbuhl N, Bozinov O, Regli L, Stienen MN (2019) Safety of resident training in the microsurgical resection of intracranial tumors: Data from a prospective registry of complications and outcome. Sci Rep 9:954

28. Zammar SG, El Tecle NE, El Ahmadieh TY, Adelson PD, Veznedaroglu E, Surdell DL, Harrop JS, Benes V, Rezai AR, Resnick DK, Bendok BR (2015) Impact of a Vascular Neurosurgery Simulation-Based Course on Cognitive Knowledge and Technical Skills in European Neurosurgical Trainees. World Neurosurg 84:197-201 